\title{
Technology for Elderly with Memory Impairment and Wandering Risk
}

\author{
Sami Perälä ${ }^{1,2 *}$, Kari Mäkelä ${ }^{2,3}$, Anna Salmenaho ${ }^{3}$, Rami Latvala ${ }^{1}$ \\ ${ }^{1}$ South Ostrobothnia Health Technology Development Centre, Seinäjoki, Finland \\ ${ }^{2}$ South Ostrobothnia Health Care District, Seinäjoki, Finland \\ ${ }^{3}$ Tampere University of Technology, Seinäjoki, Finland \\ Email: *sami.perala@eptek.fi
}

Received November 30, 2012; revised January 3, 2013; accepted January 15, 2013

\begin{abstract}
Objective: The main objective of this project was to study how to secure the wandering of elderly persons diagnosed with dementia caused by Alzheimer's disease by using healthcare technologies. Methods: The study was carried out during a three-year period (2008-2011) in the region of South Ostrobothnia, Finland. Thirty-two elderly persons living at home and diagnosed with Alzheimer's disease participated in the study. The ages of the intervention group ranged from 66 to 90 years; the average age was 81 years. A total of 63 different home care devices including 24 location based technologies were tested during the intervention. The choice of technology used was based on the individual needs of the elderly person. Results: Participants with mild stage memory impairment were able to use and benefit from the technology installed during the intervention to live more independently. The most useful devices were those that operated within the home. Nine of ten users of door alarm systems, five of nine users of GPS systems and all users of GSM systems were satisfied with the technologies. Conclusions: Location based alarm and access control technology can have a positive impact on the lives of elderly persons suffering from dementia. When chosen appropriately, technology can help to reduce or eliminate the wandering often associated with dementia. Regardless of the technology used, it should be installed when the elderly person is at the early stages of dementia; at later stages of the disease it is usually impossible for the elderly to adequately adopt the device.
\end{abstract}

Keywords: Healthcare Technology; Home Care; Gerontechnology; Wandering; Dementia; Alarm Systems

\section{Introduction}

As is well known, the elderly population of the world is increasing rapidly. According to the Center for American Progress, there were 34 million elderly Americans in 2007. According to predictions, this number could rise to 80 million by 2050 [1]. In Europe, people over the age of 75 years could form one-third of the population by 2050 [2]. This means that the number of elderly persons could more than double in Europe and North America to a total of 125 million by 2050 .

Dementia is one of the most common chronic diseases affecting elderly persons [3], Alzheimer's disease in turn is the most common form of dementia. Alzheimer's disease affects the brain, causing problems in thinking, memory and behavior. In 2006, 26.6 million people had Alzheimer's disease worldwide. By 2050, the number of people affected by Alzheimer's disease is expected to reach up to 106.4 million [4].

Finland has a high incidence Alzheimer's disease. Of a relatively small population of some 5.3 million, over

\footnotetext{
"Corresponding author.
}

120,000 persons have been diagnosed with memory impairment. Every year, there are 13,000 new cases of memory impairment diagnosed, of which seven thousand are diagnoses for persons under 65 years of age. Alzheimer's disease is the most common cause of memory impairment, accounting $60 \%$ of all cases in Finland [1, $5,6]$.

The onset of Alzheimer's disease commences the slow degradation of a patient's cognitive skills. Symptoms usually develop slowly and get progressively more severe over time. A common symptom during the disease's primary stage is temporary memory loss, more informally known as a blackout. A blackout can occur anytime and is characterized by disorientation due to the temporary memory loss. In this phase, patients are known to get lost and have a tendency to wander [7].

New technological devices and aids are constantly becoming available that can help elderly persons live safely and independently in their own homes. These devices include, for example, safety alarm phones, electronic medication dispensers and dosage medication reminders, and fall alarms. Global Positioning System (GPS) de- 
vices could in some cases potentially provide a solution to the problems encountered by persons prone to wandering behavior [7-9].

\subsection{Aim of This Study}

The main goal of this project was to study how to prevent and reduce wandering of elderly persons diagnosed with Alzheimer's disease by using alarm and tracking technologies. The target group consisted of persons between the ages of 66 to 90, who are defined as elderly for the purposes of this study.

Three different types of technologies were investigated:

- Those that are operated within the home (indoor technologies).

- Devices that are used in close proximity to the home (for example, in the garden).

- Technologies that are used outdoors at arbitrary distances from the home.

\subsubsection{Indoor Technologies}

There are numerous alarm devices available that operate within the home. These have been available for many years and they have proven to be quite reliable $[3,8]$. Security improving devices, including wireless alarm systems integrated to telecare systems, were found to be the most versatile indoor technologies installed. The devices used in this study consisted of safety phones and surveillance monitoring devices. The most commonly used devices were wrist-band alarms and fire alarm systems.

Two types of door alarms were also used in this study, one with door magnets that generates an alarm immediately after the door is opened and another with more "intelligent" functions. The alarm from both of these could be routed to highly audible sirens located within the house. Alternatively, the alarm could be routed to a call center or to relatives.

\subsubsection{Close Proximity Technologies}

Safety in the courtyard, especially to prevent unwanted exits from the yard (in close proximity to the home), was explored by testing the utility of different types of devices. Radio-frequency identification (RFID) is a technology that uses radio waves to transfer data from an electronic tag, attached to an object or person, for the purpose of identifying and tracking information embedded in the tag from several meters away and beyond sight [10]. Unfortunately, the RFID devices available for this study were found to be too unreliable, therefore the safety of the yard was secured primarily by GSM (Global System for Mobile communications) cameras where appropriate. These cameras can be connected directly to the local mobile phone GSM networks and they can be activated by motion detectors. When a motion detector indicates movement, a Multimedia Messaging Service (MMS) message is automatically transmitted to a selected GSM mobile phone number.

\subsubsection{Outdoor Technologies}

Exterior area safety was studied by testing GPS devices $[11,12]$. These have developed significantly during the past years and many solutions are currently available. In this study, we installed nine GPS devices of two different types. One was the Internet Based GPS Tracking device by LDS Group plc, and the other was a so-called full service solution by Verifi plc. The Verifi GPS servicebased system works through a call-center, which provides location details and assistance with one press of a button on the GPS device carried by a user. In addition to GPS devices, also two Radio Frequency (RF) based devices were tested, manufactured by Tracker plc.

\section{Materials and Methods}

This project was carried out in the South Ostrobothnia region of Finland during three years, starting in 2008 and was concluded by 2011. The total population of the region is about 195,000. As noted previously, the goal of this project was to study how to prevent and reduce wandering of elderly persons diagnosed with Alzheimer's disease by using alarm and tracking technologies.

The intervention group consisted of 32 participants and their family and caregivers living in three municipalities of the Health District of South Ostrobothnia. The size of the study group was relatively small because the resources available for this study were limited.

The age of the participants ranged from 66 to 90 years, the average age was 81 years. There were 13 male and 19 female participants.

The criteria for selection for the study were that all the persons were living at home in a rural region, had Alzheimer's disease and were patients of South-Ostrobothnia Health Care District. All had either a previous history of wandering, or were considered to be at risk of wandering, as determined by their caregivers or closest relatives. The final choice of the study participants was decided by the regional health care organizations responsible for individual care. It turned out that there were only 32 suitable persons that filled the criteria, so all of these were selected to the study.

The study region is predominantly rural in nature, hence most of the participants resided at relatively long distances from healthcare services.

At the beginning of the intervention, all participants were tested to determine the stage of their cognitive functions by using three commonly utilized memory tests: 
the Mini-Mental State Examination (MMSE), Clinical Dementia Rating Scale (CDR), and Reisberg Functional Assessment Staging Scale (GDS-FAST) [13].

Based on the results of these tests, the participants were then categorizes as suffering from early, mild, medium or severe stage of Alzheimer's disease. The definitions of these categories are shown in Table 1.

Once the overall status of the participants was determined, their living conditions were investigated by interviewing participants and relatives or stage holders. Based on this information, an assessment was made by a multi-professional group of the overall situation and the needs of the study participants.

In the beginning of the research, families of 12 participants were concerned about the coping ability and nine participants had problems with "getting along at home". The reasons for these problems were mainly due to aggressive behavior relatively common to a dementia patient. Patients suffered from confusion, delusions, feelings of insecurity, and from fear of thieves and peddlers. Eight patients were reported to have diurnal rhythm disorders, and 15 participants had wandered or got lost at least once prior to this intervention.

After selection of participants, a technologically experienced multi professional group of specialists decided which were the most suitable technologies for the recipients. Technologies were chosen based on the individual needs of each participant. Users' and their relatives' ability to use the devices were taken into account. The users were instructed on the use of the technologies properly and continuous technical support was available. The installed devices were first tested in a laboratory setting before the installation.

Selected technologies were set up during the second home visit and also training to use the selected devices was carried out at this stage. The correct functioning of the installed technologies was ensured by keeping in touch with the participants. All necessary home visits were made during the process. The average number of home visits was three per participant. After the intervention, the final home visit and the final estimation including interview of the participant and their relatives were carried out (Figure 1). The interviews were recorded after obtaining informed consent.

Table 1. Grading of Alzheimer's disease stages according to memory test scores.

\begin{tabular}{ccccc}
\hline Alzheimer's disease stage & Early stage & Mild stage & Medium stage & Severe stage \\
\hline Mini-Mental State Examination (MMSE) & 30 to 24 & 26 to 18 & 22 to 10 & 12 to 0 \\
Clinical Dementia Rating Scale (CDR) & 0.5 & 0.5 to 1 & 1 to 2 & 2 to 3 \\
Reisberg Functional Assessment Staging Scale (GDS-FAST) & 2 to 3 & 3 to 4 & 4 to 6 & 6 to 7 \\
\hline
\end{tabular}

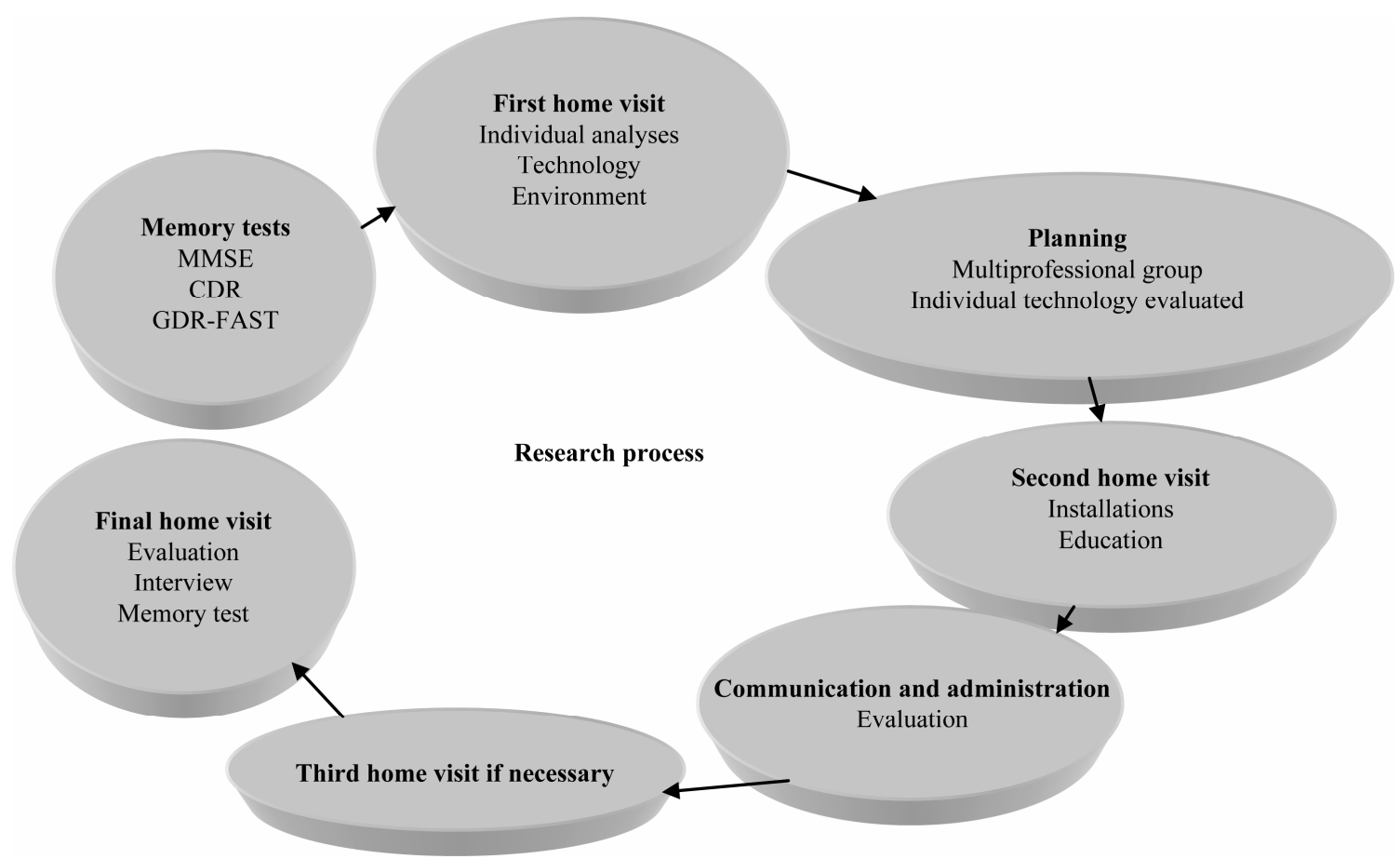

Figure 1. The steps of the intervention process. 


\section{Results}

No early stages of Alzheimer's disease were found amongst the participants at the beginning of the intervention: 12 participants were diagnosed with mild stage Alzheimer's disease, 14 participants with medium stage, and six participants with the severe stage (Table 2). At the end of the intervention, four persons were at the mild stage of Alzheimer's disease, nine at medium stage, and nine were diagnosed with the severe stage of Alzheimer's disease. Ten persons could not be tested at the end of the intervention because they moved to a care institution due to the rapid progress of their dementia prior to the termination of the intervention. At the end of the intervention, 20 participants remained at home and 12 persons were transferred to a homecare unit.

Overall, 24 location based devices were installed. In nine cases the use of technological devices proved either impractical due to the stage of memory impairment of the elderly person or otherwise unacceptable, mainly because either the relatives or the elderly persons refused to accept any type of technical device.

In addition to the main focus of this study, i.e. location specific devices, 39 other home care devices were also installed, for instance fire and stove alarms. All installed devices are shown in Table A1. Nine out of the ten users of door alarm systems, five of the nine users of GPS systems and all users of GSM system were satisfied with the technologies.

In the final evaluation at the end of the study, of those who remained at home, 16 persons continued to use a safety device. None of the participants using access control technology got lost or wandered during the intervention. In two cases, a fire alarm installed during this intervention prevented a fire. Based on the results of the final interviews, the installed technology had a positive impact on the participants; the technology helped to reduce feelings of insecurity, reduced anxiety and worry of relatives, and improved access control to homes (e.g. "stopping peddlers") (Table 2).

Overall, those technologies that operated within the premises of the living quarters, i.e. indoor technologies, tended to function more reliably than either close proximity or outdoor technologies.

\subsection{Indoor Technologies}

Magnetic door alarm systems tend not to work well for memory impairment patients, since one of the symptoms besides wandering is that the person opens the door and takes only a look outside. Therefore unnecessary alarms can occur.

Door alarms with more "intelligence" were clearly more useful and proved to operate extremely well. These devices only send an alarm to the call center or relatives when the user has actually left the building. The technology makes it possible to delay the alarm if the user, for example, walks outside to get the mail and returns to the building.

Four participants that used intelligent door alarms felt that it was helpful to them. One of the participants, who used the intelligent door alarm, was able to cope and live alone at home for more than two years even though his MMSE was 1/30 in the final evaluation. In three cases the intelligent door alarm was reported to have saved users from wandering. In two of these cases the intelligent door alarm raised an alarm and the user was found outside in cold winter weather. In one case, the intelligent door alarm exposed that the user had problems with daily rhythm and also had other problems due to dementia. One of the users (a relative) felt that the intelligent door alarm had not been helpful (Table 2).

\subsection{Close Proximity Technologies}

No appropriate commercial RFID solutions were found. None of the available RFID solutions monitored the garden area reliably enough. There are several devices that operate by utilizing short range radio frequency signals. Although these operate up to 300 meters from a central base station, none of the devices tested operated satisfactorily as there were too many false alarms triggered.

GSM-camera system technology was also used in two cases to secure the main door of the building. The primary concern in these cases was a potential external threat. Both users of the GSM camera reported at the end of the intervention that the camera "had prevented peddlers".

\subsection{Outdoor Technologies}

The LDS GPS system works well when the relatives are willing and able to use a web-based interface. The transmitter's location and movements can be followed through a web-based interface, and also virtual alarm limits can be set. Five out of nine study participants felt that the GPS systems had been useful. Four reported that the system was either too complicated or "did not work".

At the end of the project, though, only two GPS systems remained in use. The use of GPS devices proved to be too challenging for this intervention group. In several cases, the users removed the GPS tracker. The devices are also quite large in size and difficult to carry. Memory impairment users could not learn how to charge the devices' battery or did not remember to carry them in their pocket. For those users that were able to utilize the GPS trackers, the system was found useful during outdoor walks and exercising.

Two participants who used a RF (radio frequency) locator device and one participant who used a short-range 
Table 2. Summary of intervention results classified according to technology or device installed.

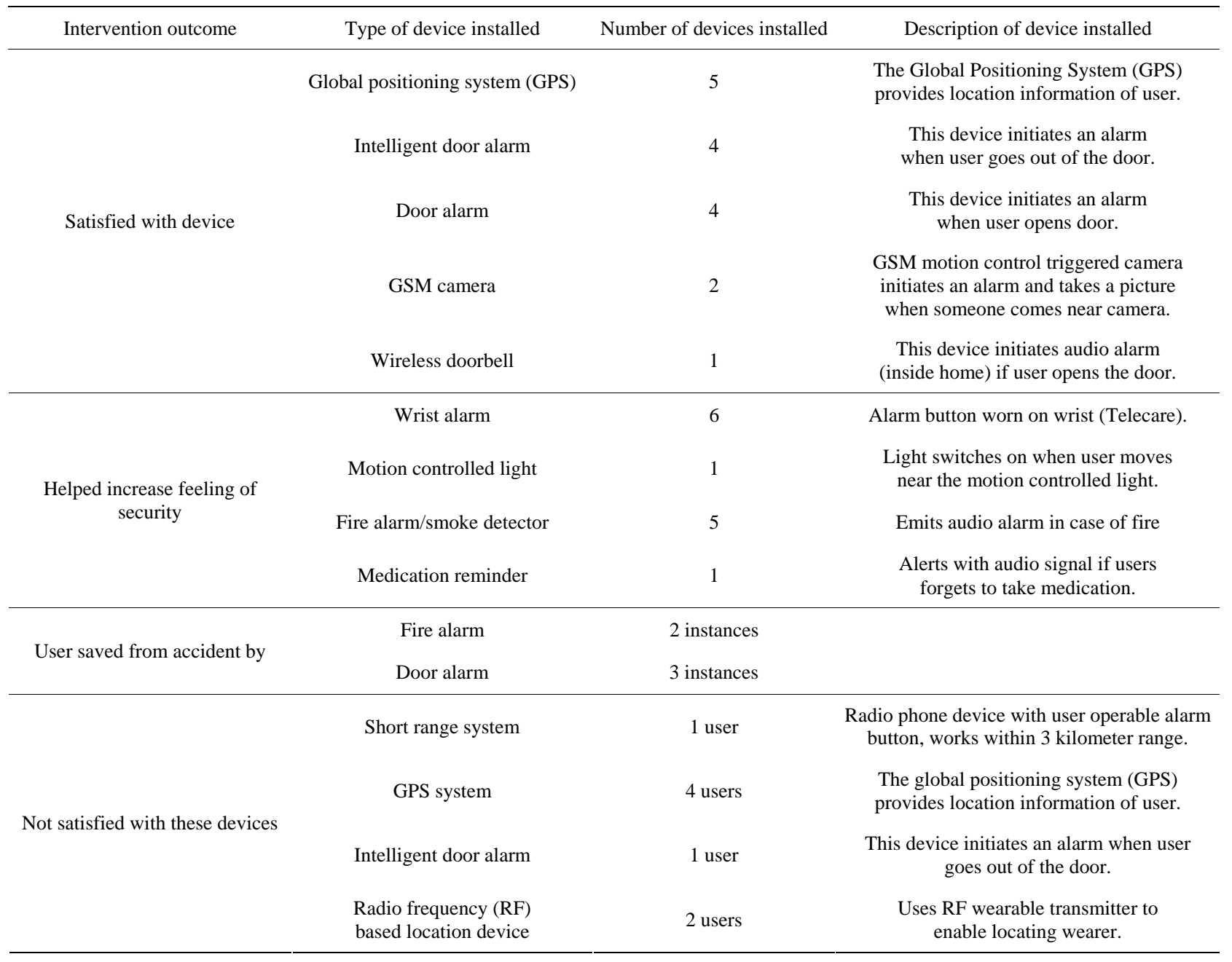

technology were not satisfied with the devices. They reported that RF based devices were difficult to use and to carry.

The limitations of the proposed home care assistive devices as well as the improvements should be discussed in the paper.

\section{Discussion}

In addition to having a positive impact for the participants, the devices also improved the overall quality of life and provided help for their relatives. For instance, the indoor alarm system with the internal audio alarm or siren can improve sleeping of the caregiver, as in many cases the patient with memory impairment suffers from sleeping problems and hence there is a risk of the patient leaving the house during the night.

There were also some clear limitations observed for indoor alarms. For instance, simple door alarm systems that activated immediately when the door was opened did not work well, as often persons suffering from dementia can just open the door to take only a look outside, without exiting. It is therefore important to understand the typical behavior of the potential user of these alarm systems, otherwise potential false alarms could severely hinder the utility of the installed devices. False alarms were also a major limitation with the tested RFID systems, as these generated far too many false alarms, mainly due to the limitations in the technology itself. An alarm could be generated if the signal from the RFID tag was blocked by heavy objects between the tag and the signal receptor. Clearly, if a system generates false alarms, its effectiveness will be severely hampered.

One significant observation was that regardless of the technology used, it should be installed when the elderly person is at the early stages of dementia; at later stages it is usually impossible for the elderly to adequately adopt the device. This is a major challenge, as the elderly persons themselves might not recognize the early stage dementia and might reject for instance tracking devices. Caregivers or relatives might similarly underestimate 
early symptoms of dementia and reject the use of appropriate technology. Dementia can progress very rapidly. Very often it will be too late to adopt a new device if the elderly person is not familiar with the device already at the early stage of the disease.

In this study we observed that people with mild stage memory impairment were able to use and benefit from the technology to live more independently. They were able to move with greater freedom and security when using GPS systems, and some were also able to take care of the devices by themselves. Persons with later stage memory impairment could not learn to utilize most of the devices appropriately. Particularly GPS devices tended to be too complex for the intervention group to use. Tasks such as charging the battery for these systems was often too challenging.

For later stages of memory impairment, the most useful devices were those that operated inside the home. Door alarm systems and even GSM cameras significantly helped those who were prone to wandering.

Statistics on how much longer the participants were able to stay home with the help of the proper technologies were not compiled. However, based on the usage of the devices, it can be argued that by using properly selected technologies, the "at home" time can be significantly longer for the elderly. Selecting the appropriate technology, however, is very challenging and requires the participation of a multi-professional group experienced in dealing with elderly persons.

The costs of the technologies were not reported as most of the devices were rented to the target group. For example, the total cost of an intelligent safety phone with integrated "door safety", including installation, is 700 EUR. The typical rental cost of the devices without other services is about 10 - 50 EUR per month. These costs are not high when compared to the achieved benefits.

\section{Conclusions}

The rapid increase in the number of elderly and memory impaired persons who can no longer look after themselves causes challenges to the homecare sector. There will be a shortage of available care personnel and appropriate care facilities. Adapting to new challenges is a major factor in ageing. While some people manage this easily, there are many who require help. The most promising strategy for limiting the demand for additional support for ageing people, is to extend the length of time they are able to remain independent in their own homes. New applications and methods of care are needed.

Some of the tested devices, for instance the GPS systems, would be vastly improved if they were better tailored to elderly persons. The procedures for battery charging should be simplified. The size of the device itself was often too large, and although this is clearly a cost issue, making devices too large to make them cheaper is counter-productive for this potential user group, as then they simply will not be adopted anyway.

With the help of new technologies ageing people can stay home longer and their safety can be improved. However, the manufacturers of these devices need to improve their understanding of the users' needs and abilities, otherwise new technology will be limited in its usefulness.

\section{Acknowledgements}

This research was supported by the European Union (EU) European Social Fund (ESF) fund as part of the "Kulkurin Valssi” Project.

\section{REFERENCES}

[1] “Long-Term Care by the Numbers," 2010. http://www.americanprogress.org/issues/2008/02/care_nu mbers.html

[2] "In Europe, Care for the Elderly Is Being Transformed," 2010.

http://www.iht.com/articles/2007/04/13/business/wbelder. php

[3] C.-C. Lin, P.-Y. Lin, P.-K. Lu, G.-Y. Hsieh, W.-L. Lee and R.-G. Lee, “A Healthcare Integration System for Disease Assessment and Safety Monitoring of Dementia Patients," IEEE Transactions on information Technology in Biomedicine, Vol. 12, No. 5, 2008, pp. 579-586.

[4] J. Geddes and W. Kevin, "Cloud Based Global Positioning System as a Safety Monitor for Dementia Patients," Cybernetic Intelligent Systems, IEEE 9th International Conference, Reading, 1-2 September 2010, pp. 1-6.

[5] “The Alzehmir Socieity of Finland,” 2012. http://www.muistiliitto.fi/eng/alzheimers_and_dementia/

[6] http://www.sgo.fi/Events/RS2012/location.php

[7] J. Loh, T. Schietecat, T. F. Kwok, L. Lindeboom and P. Joore, "Technology Applied to Address difficulties of Alzheimer Patients and Their Partners,” Dutch Directions in HCI, Amsterdam, 10 June 2004.

[8] M. Riikonen, K. Mäkelä and S. Perälä, "Safety and Monitoring Technologies for the Homes of People with Dementia," Gerontechnology, Vol. 9, No. 1, 32-45. doi:10.4017/gt.2010.09.01.003.00

[9] S. M. C. Rasquin, C. Willems, S. de Vlieger, R. P. J. Geers and M. Soede, "The Use of Technical Devices to Support Outdoor Mobility of Dementia Patients,” Technology and Disability, Vol. 19, 2007, pp. 113-120.

[10] http://www.rfidjournal.com

[11] M. Katina, A. McNamee and M. G. Michael, "The Emerging Ethics of Hemancentric GPS Tracking and Monitoring," Proceedings of the International Conference on Mobile Business, p. 34.

[12] M. Han and S. G. Xu, "Research on Data Collection and Database Update on GIS based on GPS technology," Proceedings of International, Geoscience and Remote 
Sensing Symposium, Vol. 2, 2005.

[13] M. T. Abou-Saleh, C. L. E Katona and A. Kumar, "Principles and Practise of Geriatric Psychiatry,” 3rd Edition, Wiley, 2011.

http://books.google.com/books?id=la1uAA6n2fQC\&lpg=
PA165\&ots $=5 \mathrm{fvWy}$-_Bpg\&dq=MMSE $\% 2 \mathrm{C} \% 20 \mathrm{CDR} \% 2$ C\%20GDS-FAST\%2C\%20memory\%20test\&hl=fi\&pg=P $\mathrm{R} 15 \# \mathrm{v}=$ onepage\&q=MMSE,\%20CDR,\%20GDS-FAST, \%20memory\%20test\&f=true 


\section{Appendix}

Table A1. Results of memory tests for all participants and devices installed for each intervention participant.

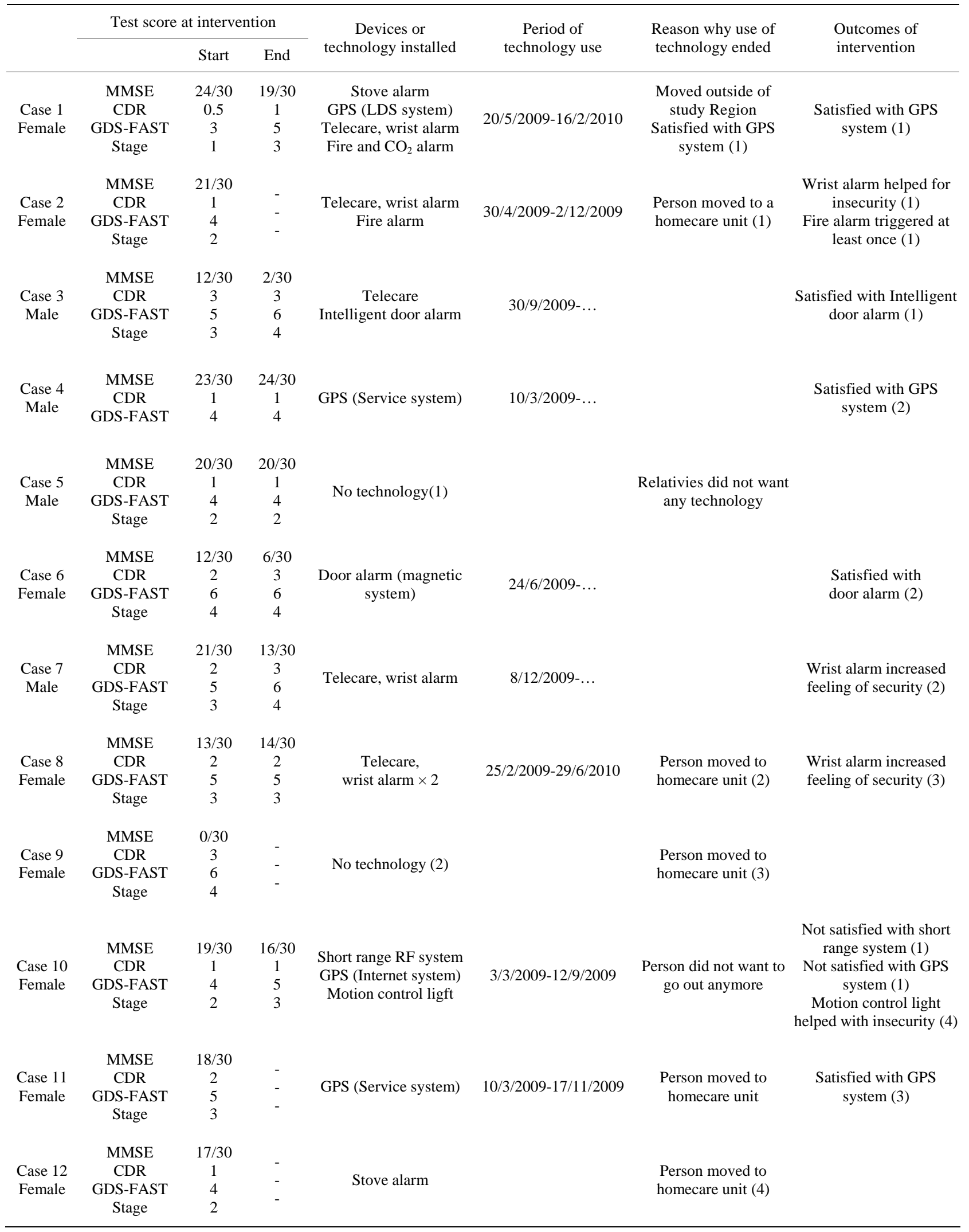




\section{Continued}

\begin{tabular}{|c|c|c|c|c|c|c|c|}
\hline $\begin{array}{l}\text { Case } 13 \\
\text { Female }\end{array}$ & $\begin{array}{l}\text { MMSE } \\
\text { CDR } \\
\text { GDS-FAST } \\
\text { Stage }\end{array}$ & $\begin{array}{c}5 / 30 \\
3 \\
7 \\
4\end{array}$ & $\begin{array}{l}- \\
- \\
-\end{array}$ & No technology (3) & & $\begin{array}{l}\text { Person moved to } \\
\text { homecare unit (5) }\end{array}$ & \\
\hline $\begin{array}{l}\text { Case } 14 \\
\text { Male }\end{array}$ & $\begin{array}{l}\text { MMSE } \\
\text { CDR } \\
\text { GDS-FAST } \\
\text { Stage }\end{array}$ & $\begin{array}{c}10 / 30 \\
2 \\
6 \\
4\end{array}$ & $\begin{array}{c}1 / 30 \\
3 \\
6 \\
4\end{array}$ & $\begin{array}{c}\text { GPS (Internet sustem) } \\
\text { Telecare + intelligent } \\
\text { door alarm }\end{array}$ & $\begin{array}{c}31 / 1 / 2008-9 / 2 / 2010 \\
15 / 1 / 2009-\ldots\end{array}$ & & $\begin{array}{l}\text { Not satisfied with GPS } \\
\text { system } \\
\text { Satisfied with intelligent } \\
\text { door alarm (3) }\end{array}$ \\
\hline $\begin{array}{l}\text { Case } 15 \\
\text { Female }\end{array}$ & $\begin{array}{l}\text { MMSE } \\
\text { CDR } \\
\text { GDS-FAST } \\
\text { Stage }\end{array}$ & $\begin{array}{c}10 / 30 \\
3 \\
6 \\
4\end{array}$ & $\begin{array}{c}10 / 30 \\
3 \\
6 \\
4\end{array}$ & No technology (4) & & $\begin{array}{l}\text { Relativies did not want } \\
\text { any technology }\end{array}$ & \\
\hline $\begin{array}{l}\text { Case } 16 \\
\text { Female }\end{array}$ & $\begin{array}{l}\text { MMSE } \\
\text { CDR } \\
\text { GDS-FAST } \\
\text { Stage }\end{array}$ & $\begin{array}{c}18 / 30 \\
1 \\
4 \\
3\end{array}$ & $\begin{array}{c}15 / 30 \\
1 \\
4 \\
3\end{array}$ & $\begin{array}{l}\text { Telecare, wrist alarm } \\
\text { Motion control light } \\
\text { Fire alarm (Siiri) } \\
\text { GSM Camera }\end{array}$ & $\begin{array}{l}1 / 4 / 2009-\ldots \\
1 / 4 / 2009-\ldots \\
4 / 6 / 2009-\ldots\end{array}$ & & $\begin{array}{c}\text { Technologies helped for } \\
\text { insecurity (5) } \\
\text { Satisfied with GSM } \\
\text { system (1) }\end{array}$ \\
\hline $\begin{array}{l}\text { Case } 17 \\
\text { Female }\end{array}$ & $\begin{array}{l}\text { MMSE } \\
\text { CDR } \\
\text { GDS-FAST } \\
\text { Stage }\end{array}$ & $\begin{array}{c}19 / 30 \\
1 \\
3 \\
2\end{array}$ & $\begin{array}{c}16 / 30 \\
1 \\
5 \\
3\end{array}$ & $\begin{array}{c}\text { Telecare, wrist alarm } \\
\text { Stove alarm } \\
\text { Medication alarm }\end{array}$ & $\begin{array}{c}\text { 26/5/2009-... } \\
6 / 8 / 2009-21 / 9 / 2009\end{array}$ & low & $\begin{array}{l}\text { Fire alarm helped for } \\
\text { insecurity (6) }\end{array}$ \\
\hline $\begin{array}{l}\text { Case } 18 \\
\text { Male }\end{array}$ & $\begin{array}{l}\text { MMSE } \\
\text { CDR } \\
\text { GDS-FAST } \\
\text { Stage }\end{array}$ & $\begin{array}{c}28 / 30 \\
2 \\
4 \\
3\end{array}$ & $\begin{array}{c}24 / 30 \\
1 \\
43\end{array}$ & $\begin{array}{c}\text { Telecare, wrist alarm } \\
\text { Intelligent door alarm } \\
\text { Door alarm (magnetic } \\
\quad \text { system) } \\
\text { GPS (Internet system) }\end{array}$ & $\begin{array}{l}3 / 12 / 2009-\ldots \\
3 / 12 / 2009-\ldots \\
28 / 1 / 2010-\ldots\end{array}$ & & $\begin{array}{c}\text { Door alarm saved (1) } \\
\text { Satisfied with Intelligent } \\
\text { door alarm (4) } \\
\text { Satisfied with door alarm } \\
\text { system (5) } \\
\text { Satisfied with GPS } \\
\text { system (4) }\end{array}$ \\
\hline $\begin{array}{l}\text { Case } 19 \\
\text { Female }\end{array}$ & $\begin{array}{l}\text { MMSE } \\
\text { CDR } \\
\text { GDS-FAST } \\
\text { Stage }\end{array}$ & $\begin{array}{c}16 / 30 \\
2 \\
5 \\
3\end{array}$ & $\begin{array}{l}- \\
- \\
-\end{array}$ & No technology (5) & & $\begin{array}{l}\text { Person moved to } \\
\text { homecare unit (6) }\end{array}$ & \\
\hline $\begin{array}{l}\text { Case } 20 \\
\text { Male }\end{array}$ & $\begin{array}{l}\text { MMSE } \\
\text { CDR } \\
\text { GDS-FAST } \\
\text { Stage }\end{array}$ & $\begin{array}{c}21 / 30 \\
1 \\
4 \\
2\end{array}$ & $\begin{array}{c}12 / 30 \\
2 \\
5 \\
3\end{array}$ & $\begin{array}{c}\text { Telecare, wrist alarm } \\
\text { Intelligent door alarm } \\
\text { Fire alarm } \\
\text { GSM Camera }\end{array}$ & $\begin{array}{c}18 / 5 / 2009-\ldots \\
18 / 5 / 2009-\ldots \\
18 / 5 / 2009-\ldots \\
4 / 6 / 2009-\ldots\end{array}$ & & $\begin{array}{c}\text { Technologies increased } \\
\text { feeling of security (6) } \\
\text { Satisfied with Intelligent } \\
\text { door alarm (6) } \\
\text { Door alarm triggered at } \\
\text { least once (2) } \\
\text { Fire alarm increased } \\
\text { feeling of security (7) } \\
\text { Satisfied with GSM } \\
\text { system (2) }\end{array}$ \\
\hline $\begin{array}{l}\text { Case } 21 \\
\text { Female }\end{array}$ & $\begin{array}{l}\text { MMSE } \\
\text { CDR } \\
\text { GDS-FAST } \\
\text { Stage }\end{array}$ & $\begin{array}{c}14 / 30 \\
2 \\
5 \\
3\end{array}$ & $\begin{array}{c}6 / 30 \\
3 \\
6 \\
4\end{array}$ & $\begin{array}{c}\text { Medication alarm } \\
\text { Door alarm (magnetic } \\
\text { system) }\end{array}$ & 24/6/2009-... & & $\begin{array}{l}\text { Technologies increased } \\
\text { feeling of security (7) } \\
\text { Satisfied with door alarm } \\
\text { system (7) }\end{array}$ \\
\hline $\begin{array}{l}\text { Case } 22 \\
\text { Male }\end{array}$ & $\begin{array}{l}\text { MMSE } \\
\text { CDR } \\
\text { GDS-FAST } \\
\text { Stage }\end{array}$ & $\begin{array}{c}22 / 30 \\
- \\
- \\
2\end{array}$ & $\begin{array}{l}- \\
-\end{array}$ & No technology (7) & & $\begin{array}{l}\text { Person moved to } \\
\text { homecare unit (7) }\end{array}$ & \\
\hline $\begin{array}{l}\text { Case } 23 \\
\text { Male }\end{array}$ & $\begin{array}{l}\text { MMSE } \\
\text { CDR } \\
\text { GDS-FAST } \\
\text { Stage }\end{array}$ & $\begin{array}{c}23 / 30 \\
1 \\
4 \\
2\end{array}$ & $\begin{array}{l}- \\
- \\
-\end{array}$ & No technology (8) & & $\begin{array}{l}\text { Person moved to } \\
\text { homecare unit (8) }\end{array}$ & \\
\hline $\begin{array}{l}\text { Case } 24 \\
\text { Male }\end{array}$ & $\begin{array}{l}\text { MMSE } \\
\text { CDR } \\
\text { GDS-FAST } \\
\text { Stage }\end{array}$ & $\begin{array}{c}15 / 30 \\
2 \\
6 \\
3\end{array}$ & $\begin{array}{c}11 / 30 \\
- \\
- \\
4\end{array}$ & GPS (Internet system) & 1/7/2009-7/9/2009 & carry GPS with him & (3) \\
\hline
\end{tabular}




\section{Continued}

\begin{tabular}{|c|c|c|c|c|c|c|c|}
\hline $\begin{array}{l}\text { Case } 25 \\
\text { Female }\end{array}$ & $\begin{array}{l}\text { MMSE } \\
\text { CDR } \\
\text { GDS-FAST } \\
\text { Stage }\end{array}$ & $\begin{array}{c}17 / 30 \\
2 \\
5 \\
3\end{array}$ & $\begin{array}{c}16 / 30 \\
2 \\
5 \\
3\end{array}$ & No technology (9) & & $\begin{array}{l}\text { Person moved to } \\
\text { homecare unit (9) }\end{array}$ & \\
\hline $\begin{array}{l}\text { Case } 26 \\
\text { Male }\end{array}$ & $\begin{array}{l}\text { MMSE } \\
\text { CDR } \\
\text { GDS-FAST } \\
\text { Stage }\end{array}$ & $\begin{array}{c}15 / 30 \\
2 \\
6 \\
3\end{array}$ & $\begin{array}{c}11 / 30 \\
2 \\
6 \\
3\end{array}$ & Telecare, wrist alarm & $1 / 3 / 2009-\ldots$ & & $\begin{array}{l}\text { Technologies increase } \\
\text { feeling of security (8) }\end{array}$ \\
\hline $\begin{array}{l}\text { Case } 27 \\
\text { Male }\end{array}$ & $\begin{array}{l}\text { MMSE } \\
\text { CDR } \\
\text { GDS-FAST } \\
\text { Stage }\end{array}$ & $\begin{array}{c}14 / 30 \\
2 \\
5 \\
3\end{array}$ & $\begin{array}{c}9 / 30 \\
3 \\
6 \\
4\end{array}$ & Intelligent door alarm & 4/6/2009-28/9/2010 & $\begin{array}{l}\text { Person moved to } \\
\text { homecare unit (10) }\end{array}$ & $\begin{array}{c}\text { Not satisfied with } \\
\text { Intelligent door alarm (1) }\end{array}$ \\
\hline $\begin{array}{l}\text { Case } 28 \\
\text { Female }\end{array}$ & $\begin{array}{l}\text { MMSE } \\
\text { CDR } \\
\text { GDS-FAST } \\
\text { Stage }\end{array}$ & $\begin{array}{c}21 / 30 \\
1 \\
5 \\
3\end{array}$ & $\begin{array}{l}- \\
-\end{array}$ & $\begin{array}{c}\text { Stove alarm } \\
\text { Fire alarm } \\
\text { RF based location device } \\
\text { Easyphone }\end{array}$ & $\begin{array}{c}6 / 3 / 2009-8 / 12 / 2009 \\
17 / 3 / 2009-2 / 10 / 2009 \\
17 / 3 / 2009-8 / 12 / 2009\end{array}$ & $\begin{array}{l}\text { Person moved to } \\
\text { homecare unit (11) }\end{array}$ & $\begin{array}{c}\text { Fire alarm triggered at } \\
\text { least once (2) } \\
\text { Fire alarm increased } \\
\text { feeling of security (9) } \\
\text { Not satisfied with RF } \\
\text { based location device (1) }\end{array}$ \\
\hline $\begin{array}{l}\text { Case } 29 \\
\text { Female }\end{array}$ & $\begin{array}{l}\text { MMSE } \\
\text { CDR } \\
\text { GDS-FAST } \\
\text { Stage }\end{array}$ & $\begin{array}{c}24 / 30 \\
1 \\
4 \\
2\end{array}$ & $\begin{array}{c}19 / 30 \\
1 \\
4 \\
2\end{array}$ & $\begin{array}{l}\text { GPS (Internet system) } \\
\text { Telecare, wrist alarm }\end{array}$ & $\begin{array}{c}15 / 6 / 2009-15 / 12 / 2009 \\
15 / 6 / 2009-2 / 6 / 2010\end{array}$ & $\begin{array}{l}\text { carry GPS with her } \\
\text { Was not necessary }\end{array}$ & (4) \\
\hline $\begin{array}{l}\text { Case } 30 \\
\text { Male }\end{array}$ & $\begin{array}{l}\text { MMSE } \\
\text { CDR } \\
\text { GDS-FAST } \\
\text { Stage }\end{array}$ & $\begin{array}{c}21 / 30 \\
1 \\
4 \\
2\end{array}$ & $\begin{array}{c}18 / 30 \\
1 \\
4 \\
2\end{array}$ & $\begin{array}{l}\text { GPS (Internet system) } \\
\text { Wireless door bell }\end{array}$ & $\begin{array}{c}\text { 3/2/2009-19/4/2010 } \\
3.2 .2009-\ldots\end{array}$ & $\begin{array}{l}\text { Person did not want to } \\
\text { go out anymore }\end{array}$ & $\begin{array}{c}\text { Satisfied with GPS } \\
\text { system (5) } \\
\text { Satisfied with wireless } \\
\text { door bell (8) }\end{array}$ \\
\hline $\begin{array}{l}\text { Case } 31 \\
\text { Female }\end{array}$ & $\begin{array}{c}\text { MMSE } \\
\text { CDR } \\
\text { GDS-FAST } \\
\text { Stage }\end{array}$ & $\begin{array}{l}- \\
- \\
- \\
2\end{array}$ & $\begin{array}{c}18 / 30 \\
- \\
- \\
2\end{array}$ & $\begin{array}{c}\text { Telecare, wrist alarm } \\
\text { Fire alarm } \\
\text { Stove alarm }\end{array}$ & $\begin{array}{l}15 / 6 / 2009-\ldots \\
15 / 6 / 2009-\ldots \\
11 / 6 / 2009-\ldots\end{array}$ & & $\begin{array}{c}\text { Fire alarm increased } \\
\text { feeling of security (10) }\end{array}$ \\
\hline $\begin{array}{l}\text { Case } 32 \\
\text { Female }\end{array}$ & $\begin{array}{c}\text { MMSE } \\
\text { CDR } \\
\text { GDS-FAST } \\
\text { Stage }\end{array}$ & $\begin{array}{c}15 / 30 \\
1 \\
5 \\
3\end{array}$ & $\begin{array}{l}- \\
- \\
-\end{array}$ & $\begin{array}{c}\text { Telecare, wrist alarm } \\
\text { Door alarm } \\
\text { (magnetic system) } \\
\text { Fire alarm } \\
\text { RF based location device } \\
\text { Stove alarm }\end{array}$ & 23/4/2009-11/10/2009 & $\begin{array}{l}\text { Person moved to } \\
\text { homecare unit (12) }\end{array}$ & $\begin{array}{c}\text { Satisfied with door alarm } \\
\text { system (9) } \\
\text { Door alarm triggered at } \\
\text { least once (3) } \\
\text { Not satisfied with RF } \\
\text { based location device (2) } \\
\text { Fire alarm increased } \\
\text { feeling of security (11) }\end{array}$ \\
\hline
\end{tabular}

Stage: 1 - 2: mild stage Alzheimer’s disease; 3: medium stage Alzheimer’s disease; 4: severe stage Alzheimer’s disease. 